\title{
MÉTODO PARA A AVALIAÇÃO DE SISTEMAS DE GESTÃO DE POKA- YOKES: ESTUDO DE CASO EM UM SISTEMA DE MANUFATURA
}

\section{METHOD TO EVALUATE POKA-YOKES MANAGEMENT SYSTEMS: CASE STUDY IN MANUFACTURING SYSTEM}

\author{
Gabriel Vidor ${ }^{1}$; Tarcísio Abreu Saurin ${ }^{2}$ \\ ${ }^{1}$ Universidade Federal do Rio Grande do Sul - UFRGS - Porto Alegre - Brasil \\ gvidor@producao.ufrgs.br \\ ${ }^{2}$ Universidade Federal do Rio Grande do Sul - UFRGS - Porto Alegre - Brasil \\ saurin@ufrgs.br
}

\begin{abstract}
Resumo
Este trabalho propõe diretrizes para avaliar sistemas de gestão de poka-yokes (SGPK). As diretrizes foram desenvolvidas após revisão da literatura e estudos de caso destinados à identificação de boas práticas em organizações do ramo metalúrgico, metal-mecânico e automotivo. Em seguida, as diretrizes foram refinadas por meio de um estudo de caso no qual elas foram aplicadas para a avaliação de sete sistemas poka-yokes em uma empresa que utiliza práticas de produção enxuta (PE). As diretrizes propõem que os poka-yokes sejam avaliados com base em um conjunto de categorias, que são desdobradas em trinta características passíveis de avaliação. A aplicação das diretrizes no estudo de caso permitiu concluir que: (a) alguns dispositivos entendidos pelas empresas como poka-yoke podem estar distantes dos atributos necessários para caracterizar os mesmos dessa forma; (b) o avaliador precisa ter conhecimento técnico do processo em que o poka-yoke está instalado; (c) as diretrizes propostas podem ser utilizadas como subsidio para o desenvolvimento de novos sistemas poka-yokes; (d) a aplicação das diretrizes tende a ser mais útil para empresas que tem iniciativas de PE, visto que estas podem visualizar o impacto sistêmico de poka-yokes.
\end{abstract}

Palavras-chave: poka-yoke; medição de desempenho, avaliação.

\section{Introdução}

Os sistemas de manufatura enxuta são afetados em seu fluxo contínuo por perdas, conforme relatam os estudos de Liker e Meier (2007). Dessa forma, a produção enxuta (PE) carece de mecanismos que garantam a continuidade de fluxo e, consequentemente, a estabilidade da produção. Dentre as estratégias para estabilização, os poka-yokes têm despertado interesse na indústria e na academia, em função da aparente simplicidade de implantação e caráter intuitivo de funcionamento. De fato, Grout (2007) e Formoso et al. (2002) relatam a aplicação de poka-yoke em 
ambientes diversos, tais como construção civil, indústria automotiva, metalúrgica, saúde, logística, entre outras. Essa abrangência mostra que os sistemas poka-yokes desempenham um papel importante na estabilidade da produção, pois, sendo esses, sinalizadores e controladores de anormalidades, quando implementados, permitem a maior autonomia dos operadores sobre o processo.

Originalmente tratado como "baka-yokes (à prova de bobos)" o sistema poka-yoke tinha por objetivo prevenir o erro humano no trabalho, visto como a principal causa dos defeitos (SHIMBUN, 1988). Com a evolução dos conceitos acerca dos sistemas poka-yokes divergências com relação ao conceito são verificadas. Há autores que entendem que os poka-yokes são limitados a dispositivos físicos que controlam defeitos (BENDELL et al., 1995), outros tem uma visão abrangente e entendem os mesmos como sistemas de garantia de qualidade e redução de variabilidade (MCGEE, 2005).

Embora a idéia de que os sistemas poka-yokes contribuem para a melhoria da qualidade dos produtos seja relativamente bem conhecida na indústria e na academia dada a sua aplicabilidade, há poucos estudos que descrevam a real extensão pela qual os poka-yokes tem sido usados e o seu real impacto nos sistemas de manufatura. Em parte, tal problema se deve a fatores como os seguintes: (a) a falta de padronização do conceito de sistema poka-yoke; (b) a ausência de métodos de avaliação da eficiência e eficácia de uso dos poka-yokes; (c) a carência de métodos para controlar o retorno econômico financeiro; (d) a utilização dos sistemas poka-yokes dissociados de perdas constadas em sistemas de manufatura; e (e) a ausência de boas práticas organizacionais, que possam ser testadas e validadas em termos científicos.

Nesse contexto verifica-se uma lacuna, visto que os sistemas poka-yokes como estão projetados e operando não atendem a critérios específicos de aplicação, que seriam a solução para a garantia de estabilidade. Idealmente um sistema poka-yoke deveria atender a critérios, que funcionariam como um indicativo das necessidades de melhoria do sistema. Uma forma de obter os indicadores de melhoria seria através de um método de avaliação dos poka-yokes.

Contudo, na literatura utilizada nesse trabalho não são disponíveis métodos de avaliação de poka-yokes. Entretanto, autores mencionam aspectos importantes para avaliar sistemas poka-yokes, como a viabilidade econômica (HINCKLEY, 2007), a gestão visual (MCGEE, 2005 CONNOR, 2006, GROUT 2007), a estabilidade da produção (LIKER e MEIER, 2007, GROUT, 2007), a manutenção (CONNOR, 2006, HINCKLEY, 2007), os princípios de projeto e operação (SHINGO, 1988, MCGEE, 2005, CONNOR, 2006, HINCKLEY, 2007, GROUT, 2007) e controle de qualidade (SHINGO, 2000). Observa-se também que não há detalhamento acerca de como realizar a avaliação segundo essas categorias e, também, nenhum estudo que considera todas as categorias simultaneamente para projeto, operação e manutenção de sistemas poka-yokes. Outra questão 
importante é que a as práticas organizacionais pesquisadas não abrangem métodos de avaliação de sistemas poka-yokes, o que configura que um método desse tipo é uma carência para as organizações que utilizam conceitos de produção enxuta.

Dessa forma, o objetivo deste artigo é desenvolver um método para a avaliação de sistemas poka-yokes, sistematizando categorias e suas características de avaliação, disponíveis na literatura e observadas no cotidiano das organizações. Além disso, pretende-se verificar o desempenho desse método com a sua validação através de um estudo de caso em um sistema de manufatura.

\section{O conceito de sistemas poka-yokes}

Os poka-yokes são aplicados em diversos contextos (logística, saúde, construção civil, tecnologia da informação), não necessariamente associados a iniciativas de implantação da PE. Contudo, nem sempre estes contextos são coincidentes, complementares, ou evoluem durante os anos, conforme se observa no Quadro 1.

No Quadro 1, observam-se as principais características conceituais de sistemas poka-yokes que são comuns a 19 conceitos distintos. Em 73\% os conceitos de poka-yoke mencionam a prevenção de defeitos ou detecção de erros, sem realizar uma diferenciação entre os conceitos de erros e defeitos. A diferenciação é importante, visto que permite classificar a função dos poka-yokes como sendo reativa (protetora) ou pró-ativa (preventiva). Conforme definição de Shingo (1996), o defeito é um dano ocorrido ao projeto de produção, seja ele um produto ou serviço. De outro lado, um erro pode ser entendido como uma falha no planejamento ou execução de uma operação (REASON, 1997), sendo normalmente a causa imediata dos defeitos. Assim, neste estudo considera-se que os poka-yokes com função reativa detectam defeitos, enquanto os poka-yokes com função pró-ativa detectam erros e, como resultado disso, previnem defeitos. 


\begin{tabular}{|c|c|}
\hline Autor/Ano & Características conceituais comuns \\
\hline $\begin{array}{l}\text { Nikkan (1988), Bendel et al. (1995), } \\
\text { Moores (1996), Ghinato (1996), Plonka } \\
\text { (1997), Fischer (1999), Patel et al. (2001a), } \\
\text { Patel et al. (2001b), Stewart e Grout (2001), } \\
\text { Formoso et al. (2002), McGee (2005). }\end{array}$ & $\begin{array}{l}\text { Os conceitos mostram que os poka-yokes são dispositivos que } \\
\text { detectam, eliminam e corrigem os erros, no mais alto nível de } \\
\text { controle sobre o processo produtivo. }\end{array}$ \\
\hline $\begin{array}{l}\text { Black (1998), Middleton (2001), Lean } \\
\text { Institute (2003), Conti et al. (2006). }\end{array}$ & $\begin{array}{l}\text { Os conceitos indicam que os poka-yokes são procedimentos, } \\
\text { métodos, técnicas usadas para eliminar o julgamento ou } \\
\text { displicência de operação e produzir com alta confiabilidade. }\end{array}$ \\
\hline $\begin{array}{l}\text { Santos e Powell (1999), Connor (2006), } \\
\text { Hinckley (2007). }\end{array}$ & $\begin{array}{l}\text { Os conceitos revelam que os poka-yokes são sistemas que } \\
\text { garantem à concepção do produto de forma óbvia, detectando ou } \\
\text { prevenindo a ocorrência de defeitos. }\end{array}$ \\
\hline $\begin{array}{l}\text { Nikkan (1988), Bendel et al. (1995), } \\
\text { Moores (1996), Ghinato (1996), Plonka } \\
\text { (1997), Black (1998), Fischer (1999), } \\
\text { Santos e Powell (1999), Middleton (2001), } \\
\text { Patel et al. (2001a), Patel et al. (2001b), } \\
\text { Stewart e Grout (2001), Formoso et al. } \\
\text { (2002), Lean Institute (2003), McGee } \\
\text { (2005), Conti et al. (2006), Connor (2006), } \\
\text { Hinckley (2007), Grout (2007). }\end{array}$ & $\begin{array}{l}\text { Os conceitos diferenciam a função reativa (detecção do erro ou } \\
\text { defeito) da função pró-ativa (prevenção do erro ou defeito) dos } \\
\text { poka-yokes. }\end{array}$ \\
\hline $\begin{array}{l}\text { Nikkan (1988), Bendel et al. (1995), } \\
\text { Moores (1996), Ghinato (1996), Plonka } \\
\text { (1997), Black (1998), Fischer (1999), } \\
\text { Santos e Powell (1999), Middleton (2001), } \\
\text { Patel et al. (2001a), Patel et al. (2001b), } \\
\text { Stewart e Grout (2001), Formoso et al. } \\
\text { (2002), Lean Institute (2003), McGee } \\
\text { (2005), Conti } \text { et al. (2006). }\end{array}$ & $\begin{array}{l}\text { Os conceitos restringem a utilização de poka-yokes a sistemas de } \\
\text { manufatura. }\end{array}$ \\
\hline $\begin{array}{l}\text { Santos e Powell (1999), McGee (2005), } \\
\text { Hinckley (2007). }\end{array}$ & $\begin{array}{l}\text { Os conceitos associam a utilização de sistemas poka-yokes à } \\
\text { estabilidade da produção. }\end{array}$ \\
\hline $\begin{array}{l}\text { Connor (2006), Hinckley (2007), Grout } \\
\text { (2007). }\end{array}$ & $\begin{array}{l}\text { Os conceitos aplicam o idéia de poka-yokes a áreas diferentes da } \\
\text { manufatura como as áreas de saúde, tecnologia da informação e } \\
\text { atividades domésticas. }\end{array}$ \\
\hline
\end{tabular}

Quadro 1 - Características de conceitos de sistemas poka-yoke

Observa-se também, no Quadro 1, que com relação à classificação dos poka-yokes, 63\% dos estudos classificam os mesmos como dispositivos, $21 \%$ como procedimentos, métodos e técnicas, e $16 \%$ como sistemas. Neste estudo, a perspectiva adotada é de que os poka-yokes são sistemas e devem ser desenvolvidos segundo um método que considere todo o seu ciclo de vida, desde a decisão de usar ou não um poka-yoke até a sua descontinuidade de uso. De fato, é necessário um sistema de gestão para poka-yoke (SGPK), possibilitando o projeto, operação, manutenção e descontinuidade do poka-yoke.

O Quadro 1 também revela quais os setores que os autores tinham em mente quando definiram o conceito de poka-yoke. Segundo esse critério, em 16\% dos casos os autores visam aplicações nas áreas da saúde, tecnologia da informação, ou mesmo nas atividades domésticas, extrapolando a limitação de manufatura imposta pelos demais $84 \%$ de definições.

Além disso, em 100\% das definições não há uma diferenciação entre os conceitos de prevenção e detecção de defeitos. Observa-se que 37\% destes conceitos associam implicitamente o 
poka-yoke a função pró-ativa (prevenção do erro e do defeito), contudo nessas mesmas definições a função reativa também é ressaltada.

Observa-se também que em 16\% das definições há uma associação entre o conceito do poka-yoke e o conceito da estabilidade da produção. Nesses conceitos o poka-yoke é mostrado como um mecanismo de garantia da estabilidade, atuando sobre a disponibilidade de recursos para o sistema de manufatura.

Essas análises subsidiam a proposição de um conceito de poka-yoke a ser usado neste trabalho. Portanto, nesse estudo os poka-yokes são definidos como sistemas destinados à prevenção e detecção de perdas de qualquer natureza (por exemplo, produtos defeituosos e acidentes de trabalho), sendo constituídos por barreiras físicas e/ou funcionais e/ou simbólicas, que contribuem para a redução da variabilidade e manutenção da estabilidade em processos. Barreiras físicas são aquelas que não permitem o transporte de massa, energia ou informação, bem como não dependem da interpretação do usuário (por exemplo, um muro). Barreiras funcionais estabelecem précondições que devem ser atendidas antes que um evento ocorra (por exemplo, uma senha). Barreiras simbólicas requerem interpretação, percepção e resposta do usuário (por exemplo, um cartaz) (HOLLNAGEL, 2004).

\section{Método de pesquisa}

A estratégia de pesquisa adotada foi o estudo de caso. Além disso, é importante ressaltar que o método de avaliação proposto está embasado nos estudos de Chiesa et al. (1996) no que tange a testes e utilização da ferramenta de auditoria.

A lógica desenvolvida nesse trabalho visa obter um método para avaliação de sistemas pokayokes. O método de avaliação foi pensado pela funcionalidade do poka-yoke e pela política da empresa em relação ao poka-yoke (posteriormente, na fase de detalhamento do método, é realizada uma explanação sobre a diferenciação desses conceitos). Além disso, foi aplicado o método Delphi para elaboração, a fim de garantir que as opiniões pessoais não estivessem sobrepostas ao julgamento coletivo nas características definidas como importantes para sistemas poka-yokes.

Na primeira fase, buscando a definição de características para avaliar sistemas poka-yokes, a revisão de literatura indicou a necessidade de classificar as características de forma sistêmica, em categorias que, quando analisadas, registrassem necessidade de melhorias. Definidas as categorias, as características foram agrupadas e submetidas à avaliação de três especialistas. A análise dessa fase permitiu que melhorias fossem realizadas no método proposto preliminarmente, com a supressão de $10 \%$ e ajuste de $26 \%$ no total de características de avaliação. 
Posteriormente aos ajustes realizados foram reunidos outros onze especialistas, permitindo que fosse realizada uma completa validação de conceito a cerca do método desenvolvido. De posse dessas informações, foi realizado com outro grupo de especialistas um teste de convergência em relação à adequabilidade das características para o contexto das organizações que utilizam sistemas poka-yokes. Terminada essa fase verificou-se homogeneidade das respostas realizadas pelos respondentes, com a obtenção de um resultado satisfatório, conforme explicita o método Delphi. Finalizando, foi elaborado o método de avaliação, com a definição de categorias e respectivas características de avaliação dos sistemas poka-yokes.

\section{Método para avaliação de um SGPK}

Nesse item é discutida a forma de elaboração do método de avaliação para o sistema de gestão de poka-yokes (SGPK). Além disso, é abordado também como utilizar o método, critérios de interpretação das fontes de evidência, perfil do avaliador e formas de validação dos resultados da avaliação.

\subsection{Fases para a elaboração do método}

O método de avaliação do SGPK foi desenvolvido em 11 etapas como mostra a Figura 1. O desenvolvimento pode ser agrupado em três fases e diversas etapas. A primeira fase pode ser chamada de averiguação e definição, onde foi realizado o levantamento bibliográfico e observações do cotidiano das organizações, em ambos os casos associados ao funcionamento dos sistemas pokayokes. A segunda fase, chamada de elaboração compreendeu a definição de um método que possibilita a avaliação de sistemas poka-yokes através de diferentes categorias e suas respectivas características. A última etapa, chamada de validação e finalização, coube a verificação do conceito e realização dos ajustes até obtenção do resultado final com a realização de um estudo de caso.

Figura 1: Método para criação do sistema de avaliação de poka-yokes

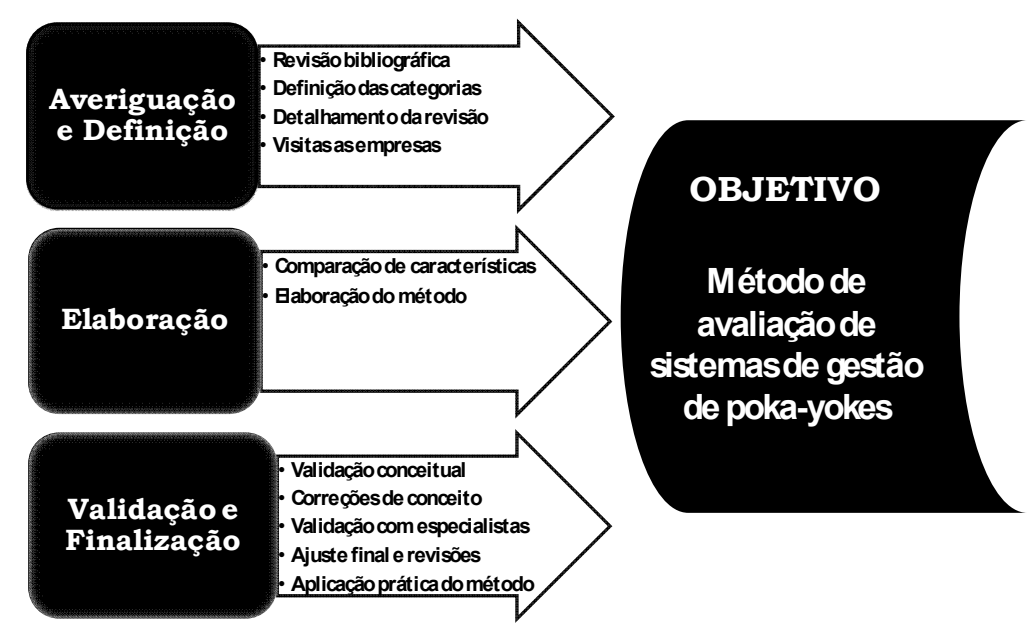


Na primeira etapa do trabalho foi realizada uma revisão sistematizada, a fim de identificar o conceito de poka-yoke e as principais categorias para avaliar esses sistemas. Por categoria entendese um grupo macro capaz de representar a essência dos sistemas poka-yokes. O resultado desta fase foi a definição do conceito de sistemas poka-yokes e também a identificação das seis categorias para sua avaliação.

Na segunda etapa definiu-se conceitualmente as seis categorias identificadas pelo estudo. A definição foi realizada associando as informações de características observadas na literatura. As categorias identificadas no estudo são as mesmas que foram apresentadas na parte inicial desse artigo. O conceito de cada categoria utilizada nesse trabalho está representado no Quadro 2.

$\mathrm{Na}$ terceira etapa foi realizado um detalhamento da revisão da literatura, a fim de definir quais seriam as características que comporiam cada categoria. Foram observadas 33 características. Dessas características, três estavam associadas à viabilidade econômica, seis à gestão visual, três à manutenção, duas à estabilidade da produção, oito ao projeto e operação e onze ao controle de qualidade. Ao fim dessa fase, foi possível estruturar uma parte do sistema de avaliação, com a classificação das características nas categorias associando as fontes bibliográficas de cada característica.

Quadro 2 - Conceitos das categorias para avaliação de sistemas poka-yokes

\begin{tabular}{|c|c|}
\hline \multicolumn{2}{|r|}{ CATEGORIAS } \\
\hline \multirow{12}{*}{ 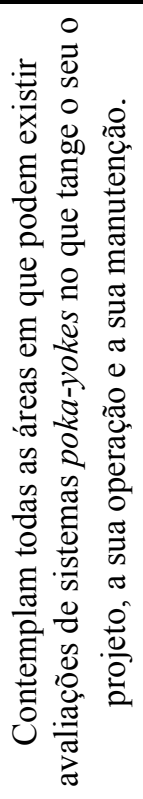 } & \begin{tabular}{|l|} 
Viabilidade económica \\
\end{tabular} \\
\hline & $\begin{array}{l}\text { Avalia se o sistema poka-yoke tem um retorno econômico-financeiro viável em } \\
\text { relação aos objetivos organizacionais. }\end{array}$ \\
\hline & \begin{tabular}{|l} 
Gestão visual \\
\end{tabular} \\
\hline & $\begin{array}{l}\text { Avalia se os aspectos visuais do sistema poka-yoke são relevantes para gestão do } \\
\text { posto de trabalho onde esse sistema está instalado. }\end{array}$ \\
\hline & Manutenção \\
\hline & $\begin{array}{l}\text { Avalia se existe manutenções preventivas e corretivas previstas no sistema poka- } \\
\text { yoke. }\end{array}$ \\
\hline & \begin{tabular}{|l|} 
Estabilidade da produção \\
\end{tabular} \\
\hline & $\begin{array}{l}\text { Avalia se existe harmonia do sistema poka-yoke com meio, máquina, mão-de- } \\
\text { obra e materiais com que interage. }\end{array}$ \\
\hline & \begin{tabular}{|l|} 
Projeto e operação \\
\end{tabular} \\
\hline & $\begin{array}{l}\text { Avalia como é a funcionalidade do sistema poka-yoke, verificando se os } \\
\text { princípios de solução estão associados as causas de problemas identificadas na } \\
\text { elaboração desse sistema. }\end{array}$ \\
\hline & Controle de qualidade \\
\hline & $\begin{array}{l}\text { Avalia de que forma o controle de qualidade, no que tange ao controle, auditoria e } \\
\text { aferição dos sistemas poka-yokes. }\end{array}$ \\
\hline
\end{tabular}

$\mathrm{Na}$ quarta etapa foram realizadas visitas a empresas com práticas de PE, e que utilizam sistemas poka-yokes em seu cotidiano, com o objetivo de identificar as fontes de evidência de cada característica. Foram três as empresas visitadas. Essas companhias caracterizam-se por serem de grande porte, sendo multinacionais de capital aberto. As visitas foram importantes porque 
auxiliaram a identificar as fontes de evidência a serem observadas na avaliação de poka-yoke, além de boas práticas no que tange à gestão de poka-yokes. Constatou-se que as fontes de evidência são a principal fonte de comparação com a realidade organizacional.

$\mathrm{Na}$ quinta etapa foram realizadas comparações entre as características identificadas, a fim de definir relações de características nas categorias criadas. Finalizada essa fase, foram iniciados trabalhos para a modificação dos totais de características das categorias controle de qualidade e estabilidade da produção, transferindo-se uma característica do controle de qualidade para estabilidade da produção, passando, respectivamente, a dez e três características.

$\mathrm{Na}$ sexta etapa foi realizada a construção do método, através da sistematização das categorias e suas características, das fontes bibliográficas e fontes de evidência associadas nas características. Nessa fase, foi associado também o conceito de PE a cada característica. O conceito de PE adotado para classificar as características foi o adotado pelos autores Liker e Meier (2007). A escolha deve-se ao fato dos autores serem referência no cenário mundial em relação ao assunto. Nessa etapa foram atribuídos números para características, sempre obedecendo à representação de dois números precedidos pelas letras referentes a cada categoria. Por exemplo, a característica quatro foi identificada como GV04 (onde GV equivale à gestão visual). A sistemática desenvolvida apresenta uma planilha com organização em colunas dos grupos de categorias, suas características, fontes bibliográficas, fontes de evidência e o conceito de PE.

Na sétima etapa foi realizada uma validação conceitual com três especialistas em PE. Esses especialistas são pessoas com experiência de dois a quatro anos em produção enxuta e que atualmente estão desenvolvendo seus trabalhos de mestrado e doutorado associados a este tema. Além disso, os especialistas têm realizado intervenções em organizações auxiliando no desenvolvimento da produção enxuta nesses ambientes. A validação conceitual permitiu que fossem realizados ajustes significativos em relação ao método de avaliação desenvolvido.

A primeira modificação foi em relação ao número de características, reduzido de 33 para 30 . Foram eliminadas duas características da categoria viabilidade econômica e outra em relação a categoria controle de qualidade. Conforme julgamento dos especialistas, essas três características estavam duplicadas em relação a outras características já apresentadas.

A segunda modificação está associada ao tipo das características. As 30 características eram dos variáveis contínuas e atributos. Após análise dos especialistas optou-se por transformar todas as características para o tipo atributos, sob o argumento que é mais importante verificar se um determinado sistema poka-yoke apresenta ou não a característica, ao invés de mensurar a sua importância quantitativamente, visto que essa medição implicaria na identificação de um modelo para cada sistema de manufatura em uma organização (ou mesmo, diferença nos sistemas de 
manufatura dentro da mesma empresa) que utilizasse o método de avaliação, dada a importância atribuída em menor ou maior grau para cada característica.

A terceira modificação realizada foi a diferenciação das características pela funcionalidade do poka-yoke ou pela política da empresa em relação ao sistema poka-yoke. Essa diferenciação permite mostrar o que está relacionado à operação do sistema poka-yoke e o que depende de uma política organizacional para ser realizada. Por exemplo: a característica CQ24 após a modificação ficou detalhada da seguinte forma - a funcionalidade atesta a eficácia do sistema poka-yoke, e ao mesmo tempo a empresa deve ter a política de desenvolver procedimentos para auxiliar na verificação de funcionamento a cada início da jornada de trabalho. Verifica-se que a característica é similar no que tange a eficácia, todavia a primeira parte está associada à função do sistema pokayoke e deve existir independentemente do tipo de organização; já a segunda parte está associada à forma de trabalho da empresa, podendo ser implementada de acordo com a filosofia de trabalho de cada organização.

A última modificação foi em relação ao agrupamento das características nas categorias. A análise com especialistas permitiu a migração de características entre as categorias definidas. $\mathrm{O}$ reagrupamento proposto envolveu uma característica na categoria viabilidade econômica, seis na categoria gestão visual, quatro na categoria manutenção, quatro na categoria estabilidade da produção, seis categoria na categoria projeto e operação, e nove na categoria controle de qualidade.

Apoiado por todas essas informações, na oitava fase foi realizada uma readequação do sistema de avaliação elaborado na etapa seis. Não foi realizada uma mudança significativa na forma de apresentação, continuando a organização das características em colunas justapostas com as respectivas informações relatadas anteriormente. Além disso, foi realizada uma revisão da descrição das características.

$\mathrm{Na}$ nona etapa foi realizada uma validação final do método com onze especialistas. Nenhum desses especialistas havia sido envolvido nas fases anteriores. Os especialistas caracterizam-se por serem todos engenheiros de produção, com experiência profissional entre cinco e dez anos, em organizações que utilizam práticas de PE em seu cotidiano, sendo que $82 \%$ atuam na indústria e o restante no ramo de serviços. Além disso, 90\% apresentam formação específica na área de PE. Nessa etapa todas as 30 características foram modificadas em sua descrição, sendo que a mudança mais significativa estava relacionada às categorias de projeto e operação e controle de qualidade. $\mathrm{Na}$ categoria de projeto e operação foram realizadas três modificações integrais, que podem ser entendidas como a substituição da característica original por outra de igual sentido, mas de descrição totalmente diferente da descrição anteriormente desenvolvida. Na categoria de controle de qualidade foram modificadas integralmente duas características, e parcialmente outras duas. A justificativa para a modificação das características foi a necessidade de adequação dos termos. $\mathrm{Na}$ 
maior parte das ocasiões os termos encontravam-se defasados em relação ao praticado no cotidiano das organizações, o que acabaria por prejudicar a análise de quem utilizasse o método de avaliação de sistemas poka-yokes.

$\mathrm{Na}$ décima etapa foram realizados os ajustes a partir das sugestões dos especialistas e revisão final. Nessa etapa foi realizada uma adequação visual do que estava sendo proposto, a fim de facilitar a manipulação no momento da avaliação. Outro aspecto ajustado foi em relação ao conceito de PE associado, como houve mudanças nas descrições das características foi necessário também revisar esse conceito associado a cada característica.

A etapa final compreendeu a aplicação do método desenvolvido a partir das etapas anteriores. A validação foi realizada com intuito de obter informações relevantes para as etapas de elaboração metodológica, validando em termos práticos o conceito desenvolvido.

\subsection{Definição do método de avaliação}

O Quadro 3 ilustra o método para avaliação de SGPK desenvolvido por meio dos procedimentos descritos no item anterior. É possível observar que o método apresenta as categorias e as respectivas características dos SGPK. As características estão divididas em características de funcionalidade do poka-yoke e características de política da empresa, respectivamente nas colunas B e C. A funcionalidade está associada ao objetivo para qual o sistema foi criado e deve fazer parte de qualquer sistema poka-yoke, independentemente da empresa, sistema de manufatura ou processo em que foi implementado. A política da empresa está relacionada ao tratamento que a empresa atribui ao processo que tem um sistema poka-yoke associado. Essa diferenciação é importante, porque permite ao avaliador definir se as melhorias dos sistemas poka-yokes podem ser relacionadas a funcionalidade do sistema, ou se é necessário o desenvolvimento de uma política institucional, como normas para aferição e verificação dos sistemas.

$\mathrm{Na}$ coluna A está mostrado o código da característica do sistema poka-yoke. O código é composto por duas letras (variando conforme e categoria) de dois números (sequenciais da primeira a última característica). A codificação é importante para que o avaliador possa utilizar a planilha de forma fácil, tornando rápida e produtiva a avaliação. 
Quadro 3 - Categorias e características para avaliação de sistemas poka-yokes

\begin{tabular}{|c|c|c|c|c|c|}
\hline & \multicolumn{2}{|c|}{ Viabilidade econômica do poka-yoke } & $\begin{array}{c}\text { Fontes } \\
\text { Bibliográficas }\end{array}$ & Fontes de evidência & $\begin{array}{l}\text { Princípio de PE } \\
\text { associado }\end{array}$ \\
\hline & \multicolumn{2}{|c|}{ Características do poka-yoke } & & & \\
\hline & $\begin{array}{l}\text { Funcionalidade do poka- } \\
\text { yoke }\end{array}$ & Política da empresa & & & \\
\hline \multirow[t]{4}{*}{ VE01 } & - & $\begin{array}{l}\text { O retorno de investimento } \\
\text { em relação ao poka-yoke } \\
\text { atende todas as expectativas } \\
\text { da organização quanto a } \\
\text { custos e prazos } \\
\text { estabelecidos. }\end{array}$ & Hincley (2007) & $\begin{array}{l}\text { Documentação, ou } \\
\text { arquivo, sobre o cálculo } \\
\text { de viabilidade } \\
\text { econômica. }\end{array}$ & $\begin{array}{l}\text { Controle de } \\
\text { perdas }\end{array}$ \\
\hline & \multicolumn{2}{|c|}{ Gestão visual do poka-yoke } & $\begin{array}{c}\text { Fontes } \\
\text { Bibliográficas }\end{array}$ & Fontes de Evidência & $\begin{array}{l}\text { Princípio de PE } \\
\text { associado }\end{array}$ \\
\hline & \multicolumn{2}{|c|}{ Características do poka-yoke } & & & \\
\hline & $\begin{array}{l}\text { Fucionalidade do poka- } \\
\text { yoke }\end{array}$ & Política da Empresa & & & \\
\hline GV 02 & $\begin{array}{l}\text { Existe uma } \\
\text { documentação que } \\
\text { detalha como operar o } \\
\text { poka-yoke, especificando } \\
\text { todas as características } \\
\text { do mesmo. }\end{array}$ & - & $\begin{array}{l}\text { McGee (2005), } \\
\text { Connor (2006), } \\
\text { Grout (2007) }\end{array}$ & $\begin{array}{l}\text { Instrução de trabalho da } \\
\text { organização, } \\
\text { padronizada conforme } \\
\text { seu sistema de gestão }\end{array}$ & Padronização \\
\hline GV 03 & $\begin{array}{l}\text { Nas estações de trabalho } \\
\text { ou máquinas em que o } \\
\text { poka-yoke é } \\
\text { implementado, existe } \\
\text { uma instrução de } \\
\text { trabalho explicando } \\
\text { detalhadamente como } \\
\text { realizar veriicação } \\
\text { funcional do poka-yoke. }\end{array}$ & $\begin{array}{l}\text { A empresa tem uma política } \\
\text { para dispor as peças } \\
\text { suspeitas analisadas em cada } \\
\text { verificação funcional do } \\
\text { poka-yoke. }\end{array}$ & $\begin{array}{l}\text { Connor (2006), } \\
\text { Grout (2007) }\end{array}$ & $\begin{array}{l}\text { Instrução de trabalho da } \\
\text { organização, } \\
\text { padronizada conforme } \\
\text { seu sistema de gestão }\end{array}$ & Padronização \\
\hline GV 04 & - & $\begin{array}{l}\text { Existe uma identificação } \\
\text { (fixação de etiquetas) e } \\
\text { detalhamento de instruções } \\
\text { de trabalho do processo em } \\
\text { que há a implementação dos } \\
\text { poka-yokes. }\end{array}$ & $\begin{array}{l}\text { McGee (2005), } \\
\text { Hinckley } \\
(2007)\end{array}$ & $\begin{array}{l}\text { Etiqueta de } \\
\text { indentificação de } \\
\text { melhoria e/ou } \\
\text { implementação de um } \\
\text { poka-yoke. }\end{array}$ & Melhoria contínua \\
\hline GV05 & - & $\begin{array}{l}\text { Existe em cada estação de } \\
\text { trabalho a explicação do } \\
\text { procedimento de operação da } \\
\text { máquina ou processo. Nesta } \\
\text { explicação está contida a } \\
\text { explicação em relação ao } \\
\text { sistema }\end{array}$ & $\begin{array}{l}\text { McGee (2005), } \\
\text { Connor (2006), } \\
\text { Grout (2007) }\end{array}$ & $\begin{array}{l}\text { Instrução de trabalho da } \\
\text { organização, } \\
\text { padronizada conforme } \\
\text { seu sistema de gestão. }\end{array}$ & Padronização \\
\hline GV06 & - & $\begin{array}{l}\text { Melhorias observadas com a } \\
\text { implementação de poka- } \\
\text { yokes são destacadas em } \\
\text { todos os processos em que } \\
\text { ocorreram. }\end{array}$ & $\begin{array}{l}\text { Shingo (2005), } \\
\text { McGee (2005), } \\
\text { Hinckley } \\
(2007), \text { Grout } \\
(2007)\end{array}$ & $\begin{array}{l}\text { Indicador de eficiência } \\
\text { do poka-yoke, que } \\
\text { mede quandidade de } \\
\text { efeito de retrabalho, } \\
\text { mostrando a diferença } \\
\text { entre e depois da } \\
\text { implantação. }\end{array}$ & Melhoria contínua \\
\hline \multirow[t]{4}{*}{ GV07 } & - & $\begin{array}{l}\text { A gestão visual utilizada no } \\
\text { poka-yoke é padrão e } \\
\text { regulada por uma } \\
\text { normatização da empresa. }\end{array}$ & Grout (2007) & $\begin{array}{l}\text { Procedimento padrão } \\
\text { da empresa de como } \\
\text { gerir visualmenteo seu } \\
\text { poka-yoke. }\end{array}$ & Padronização \\
\hline & \multicolumn{2}{|l|}{ Manutenção do poka-yoke } & $\begin{array}{l}\text { Fontes } \\
\text { bibliográficas }\end{array}$ & Fontes de evidência & $\begin{array}{l}\text { Princípio de PE } \\
\text { associado }\end{array}$ \\
\hline & \multicolumn{2}{|l|}{ Características do poka-yoke } & & & \\
\hline & $\begin{array}{l}\text { Funcionalidade do poka- } \\
\text { yoke }\end{array}$ & Política da empresa & & & \\
\hline MA08 & $\begin{array}{l}\text { Existe um plano de } \\
\text { manutenção preventiva } \\
\text { para o poka-yoke que } \\
\text { está sendo auditado }\end{array}$ & - & $\begin{array}{l}\text { Conor (2006), } \\
\text { Hinckley } \\
(2007)\end{array}$ & $\begin{array}{l}\text { Plano de ação de } \\
\text { manutenção da } \\
\text { aorganização e hitórico } \\
\text { de manutenção }\end{array}$ & $\begin{array}{l}\text { Controle de } \\
\text { perdas }\end{array}$ \\
\hline
\end{tabular}




\begin{tabular}{|c|c|c|c|c|c|}
\hline & & & & preventiva & \\
\hline MA09 & $\begin{array}{l}\text { Existe um histórico de } \\
\text { manutenção corretiva } \\
\text { para o poka-yoke e que } \\
\text { está sendo auditado. }\end{array}$ & - & $\begin{array}{l}\text { Conor (2006), } \\
\text { Hinckley } \\
(2007)\end{array}$ & $\begin{array}{l}\text { Relatório de incidências } \\
\text { de manutenção } \\
\text { corretiva. }\end{array}$ & $\begin{array}{l}\text { Controle de } \\
\text { perdas }\end{array}$ \\
\hline MA10 & - & $\begin{array}{l}\text { Existe um plano de } \\
\text { manutenção preventiva para } \\
\text { todas a estação de trabalho, e } \\
\text { o poka-yoke é tratado como } \\
\text { parte dessa estação de } \\
\text { trabalho. }\end{array}$ & Conor (2006) & $\begin{array}{l}\text { Plano de açào de } \\
\text { manutenção da } \\
\text { organização e histórico } \\
\text { de mantenção } \\
\text { preventiva. }\end{array}$ & $\begin{array}{l}\text { Controle de } \\
\text { perdas }\end{array}$ \\
\hline \multirow[t]{4}{*}{ MA11 } & $\begin{array}{l}\text { A manutenção no poka- } \\
\text { yoke auditado é do } \\
\text { tipocorretiva e realizada } \\
\text { de acordo com a } \\
\text { necessidade. }\end{array}$ & (1) & $\begin{array}{l}\text { Hinck ley } \\
(2007)\end{array}$ & $\begin{array}{l}\text { Depoimento dos } \\
\text { operadores que utilizam } \\
\text { o sistema poka-yoke. }\end{array}$ & Automação \\
\hline & \multicolumn{2}{|c|}{ Estabilidade de produção e poka-yoke } & $\begin{array}{l}\text { Fontes } \\
\text { bibliográficas }\end{array}$ & Fontes de evidência & $\begin{array}{l}\text { Princípio de PE } \\
\text { associado }\end{array}$ \\
\hline & \multicolumn{2}{|l|}{ Caracteísticas do poka-yoke } & & & \\
\hline & $\begin{array}{l}\text { Funcionalidade do poka- } \\
\text { yoke }\end{array}$ & Política da empresa & & & \\
\hline EP12 & $\begin{array}{l}\text { O poka-yoke previne } \\
\text { (impede a ocorrência) a } \\
\text { instabilidade e sinaliza a } \\
\text { anormalidade. }\end{array}$ & $\begin{array}{l}\text { O processo reinicia com o } \\
\text { trabalho da(s) causa(s) do(s) } \\
\text { problema(s). }\end{array}$ & $\begin{array}{l}\text { Hinckley } \\
(2007), \\
\text { Grout (2007) }\end{array}$ & $\begin{array}{l}\text { Projeto do poka-yoke e } \\
\text { observação do } \\
\text { funcionamento do } \\
\text { processo na } \\
\text { organização }\end{array}$ & Automação \\
\hline EP13 & $\begin{array}{l}\text { Poka-yoke detecta (evita } \\
\text { propagação) a } \\
\text { instabilidade e sinaliza a } \\
\text { anormalidade. }\end{array}$ & $\begin{array}{l}\text { O processo reinicia com a } \\
\text { autorizaçào da pessoa } \\
\text { apropriada }\end{array}$ & $\begin{array}{l}\text { Hinckley } \\
(2007), \\
\text { Grout (2007) }\end{array}$ & $\begin{array}{l}\text { Projeto do poka-yoke e } \\
\text { observação do } \\
\text { funcionamento do } \\
\text { processo na } \\
\text { organização }\end{array}$ & Automação \\
\hline EP14 & - & $\begin{array}{l}\text { As peças produzidas que são } \\
\text { verificadas por poka-yokes } \\
\text { estão dentro da variabilidade } \\
\text { aceitável. }\end{array}$ & $\begin{array}{l}\text { Shingo (1998), } \\
\text { McGee (2005), } \\
\text { Connor (2006), } \\
\text { Hinckley } \\
(2007), \text { Grout } \\
(2007)\end{array}$ & $\begin{array}{l}\text { Indicador de eficiência, } \\
\text { mede o turm over no } \\
\text { processo. Compara o } \\
\text { antes e depois da } \\
\text { implementação do } \\
\text { poka-yoke. }\end{array}$ & Melhoria contínua \\
\hline \multirow[t]{4}{*}{ EP15 } & $\begin{array}{l}\text { A implementação do } \\
\text { poka-yoke assegura } \\
\text { melhorias no } \\
\text { respectivo(a) processo } \\
\text { ou operação. }\end{array}$ & - & $\begin{array}{l}\text { Shingo (1998), } \\
\text { McGee (2005), } \\
\text { Connor (2006), } \\
\text { Hinckley } \\
(2007) \text {, Grout } \\
(2007)\end{array}$ & $\begin{array}{l}\text { Indicador de eficiencia, } \\
\text { mede o tum over no } \\
\text { processo. Compara o } \\
\text { antes e o depois da } \\
\text { implementação do } \\
\text { poka-yoke. }\end{array}$ & Melhoria contínua \\
\hline & \multicolumn{2}{|c|}{ Projeto e operação poka-yoke } & $\begin{array}{l}\text { Fontes } \\
\text { bibliográficas }\end{array}$ & Fontes de evidência & $\begin{array}{l}\text { Principio de } \\
\text { PE associado }\end{array}$ \\
\hline & \multicolumn{2}{|c|}{ Características do poka-yoke } & & & \\
\hline & Funcionalidade & Política da empresa & & & \\
\hline PO 16 & $\begin{array}{l}\text { O poka-yoke está } \\
\text { projetado e operando } \\
\text { para combater a causa } \\
\text { raiz identificada } \\
\text { anteriormente a sua } \\
\text { concepção } \\
\end{array}$ & & $\begin{array}{l}\text { McGee (2005) } \\
\text { Hinck ley } \\
(2007) \\
\text { Grount (2007) }\end{array}$ & $\begin{array}{l}\text { Projeto de poka-yoke e } \\
\text { documentação de } \\
\text { identificação de causa } \\
\text { raiz (FMEA, FTA, } \\
\text { Planilha de } \\
\text { braistorming, etc. }\end{array}$ & Melhoria contínua \\
\hline PO 17 & & $\begin{array}{l}\text { Segurança do operador foi } \\
\text { considerada na concepção do } \\
\text { projeto do poka-yoke. }\end{array}$ & $\begin{array}{l}\text { Connor (2006) } \\
\text { Hinck ley } \\
(2007) \\
\text { Grout }(2007)\end{array}$ & $\begin{array}{l}\text { Parecer da área de } \\
\text { saúde, segurança e } \\
\text { meio ambiente no } \\
\text { projeto de } \\
\text { desenvolvimento. }\end{array}$ & $\begin{array}{l}\text { Controle de } \\
\text { perdas }\end{array}$ \\
\hline PO 18 & & $\begin{array}{l}\text { A flexibilidade do operador } \\
\text { foi considerada na } \\
\text { concepção de projeto poka- } \\
\text { yoke. }\end{array}$ & $\begin{array}{l}\text { Connor (2006) } \\
\text { Hinck ley } \\
(2007) \\
\text { Grout }(2007)\end{array}$ & $\begin{array}{l}\text { Parecer da área de } \\
\text { saúde, segurança e } \\
\text { meio ambiente no } \\
\text { projeto de } \\
\text { desenvolvimento. }\end{array}$ & $\begin{array}{l}\text { Controle de } \\
\text { perdas }\end{array}$ \\
\hline PO 19 & $\begin{array}{l}\text { O projeto do poka-yoke } \\
\text { foi pensado para } \\
\text { combinar a operação de } \\
\text { inspeção e o sistema } \\
\text { poka-yoke. }\end{array}$ & & Shingo (1988) & Projeto do poka-yoke. & $\begin{array}{l}\text { Controle de } \\
\text { perdas }\end{array}$ \\
\hline
\end{tabular}




\begin{tabular}{|c|c|c|c|c|c|}
\hline PO 20 & $\begin{array}{l}\text { O poka-yoke está } \\
\text { projatado e operando } \\
\text { para combater as causas } \\
\text { secundárias identificadas } \\
\text { anteriormente a sua } \\
\text { concepção }\end{array}$ & & $\begin{array}{l}\text { Hinck ley } \\
(2007) \\
\text { Grout (2007) }\end{array}$ & $\begin{array}{l}\text { Projeto de poka-yoke e } \\
\text { documentação de } \\
\text { indentificação de } \\
\text { causas e problemas } \\
\text { (FMEA, FTA, Planilha } \\
\text { de braistorming) }\end{array}$ & $\begin{array}{l}\text { Controle de } \\
\text { perdas }\end{array}$ \\
\hline PO 21 & & $\begin{array}{l}\text { O projeto e implementação } \\
\text { do sistema poke-yoke foi } \\
\text { desenvolvido com a } \\
\text { participação da equipe } \\
\text { multifuncional. }\end{array}$ & $\begin{array}{l}\text { Shingo (1988). } \\
\text { McGee (2005) } \\
\text { Connor (2006) } \\
\text { Grout (2007) }\end{array}$ & $\begin{array}{l}\text { Documentação do } \\
\text { projeto de } \\
\text { desenvolvimento. }\end{array}$ & Automação \\
\hline PO 22 & $\begin{array}{l}\text { O poka-yoke tem função } \\
\text { pró-ativa, onde peças } \\
\text { não conforme não são } \\
\text { produzidas }\end{array}$ & & $\begin{array}{l}\text { Shingo (1988). } \\
\text { McGee (2005) } \\
\text { Connor (2006) } \\
\text { Grout (2007) }\end{array}$ & $\begin{array}{l}\text { Funcionamento do } \\
\text { poka-yoke in loco e } \\
\text { observação do processo }\end{array}$ & $\begin{array}{l}\text { Controle de } \\
\text { perdas }\end{array}$ \\
\hline PO 23 & & $\begin{array}{l}\text { O poka-yoke é aferido } \\
\text { regularmente, conforme } \\
\text { exigências normativas em } \\
\text { vigor. }\end{array}$ & Grout (2007) & $\begin{array}{l}\text { Documentação com } \\
\text { histórico de verificação } \\
\text { do poka-yoke. }\end{array}$ & Padronização \\
\hline PO 24 & $\begin{array}{l}\text { O procedimento de } \\
\text { início de jornada atesta } \\
\text { em } 100 \% \text { a eficácia do } \\
\text { sistema poka-yoke }\end{array}$ & $\begin{array}{l}\text { O poka-yoke apresenta um } \\
\text { procedimento para } \\
\text { verificação de funciona a } \\
\text { cada início da jornada de } \\
\text { trabalho }\end{array}$ & Grout (2007) & $\begin{array}{l}\text { Instrução de trabalho } \\
\text { que mostra como é o } \\
\text { procedimento de } \\
\text { verificação do poka- } \\
\text { yoke }\end{array}$ & Padronização \\
\hline PO 25 & & $\begin{array}{l}\text { O poka-yoke está integrado a } \\
\text { outras ferramentas de gestão } \\
\text { da qualidade. }\end{array}$ & $\begin{array}{l}\text { Hinck ley } \\
(2007)\end{array}$ & $\begin{array}{l}\text { Sistema de gestão da } \\
\text { qualidade sendo que o } \\
\text { poka-yoke é um } \\
\text { elemento caracterizado } \\
\text { e com vida própria } \\
\text { nesse sistema de gestão }\end{array}$ & Melhoria contínua \\
\hline PO 26 & $\begin{array}{l}\text { O poka-yoke realiza } \\
\text { inspeção } 100 \% \\
\text { automática } \\
\end{array}$ & & $\begin{array}{l}\text { Shingo (1988). } \\
\text { Grout (2007) }\end{array}$ & $\begin{array}{l}\text { Funcionamento do } \\
\text { poka-yoke in loco e } \\
\text { observação de processo }\end{array}$ & $\begin{array}{l}\text { Controle de } \\
\text { perdas }\end{array}$ \\
\hline PO 27 & $\begin{array}{l}\text { A implantação do poka- } \\
\text { yoke gerou algum nível } \\
\text { e redução de defeitos ao } \\
\text { longo do tempo. }\end{array}$ & & & $\begin{array}{l}\text { Indicador de eficiência, } \\
\text { mede o percentual de } \\
\text { intens com defeitos, } \\
\text { comparando antes e } \\
\text { depois da } \\
\text { implementação do } \\
\text { poka-yoke. }\end{array}$ & $\begin{array}{l}\text { Controle de } \\
\text { perdas }\end{array}$ \\
\hline PO 28 & $\begin{array}{l}\text { O poka-yoke tem a } \\
\text { função reativa, onde } \\
\text { peças não conforme sãs } \\
\text { detectadas e desviadas. }\end{array}$ & & $\begin{array}{l}\text { Shingo (1988) } \\
\text { Hinckey } \\
(2007) \\
\text { Grout (2007) }\end{array}$ & $\begin{array}{l}\text { Funcionamento do } \\
\text { poke-yoke in loco e } \\
\text { observação de } \\
\text { processo. }\end{array}$ & $\begin{array}{l}\text { Controle de } \\
\text { perdas }\end{array}$ \\
\hline PO 29 & $\begin{array}{l}\text { O poka-yoke tem função } \\
\text { reativa, onde peças não } \\
\text { conforme são detectadas } \\
\text { e desviadas. }\end{array}$ & & Connor (2006) & $\begin{array}{l}\text { Indicador de eficiência, } \\
\text { que mede a variação da } \\
\text { característica ao longo } \\
\text { do tempo. }\end{array}$ & $\begin{array}{l}\text { Controle de } \\
\text { perdas }\end{array}$ \\
\hline PO 30 & $\begin{array}{l}\text { O poka- yoke segue } \\
\text { padronização para } \\
\text { verificar itens }\end{array}$ & & $\begin{array}{l}\text { Shingo (1988) } \\
\text { Grout (2007) }\end{array}$ & $\begin{array}{l}\text { Funcionamento do } \\
\text { poke-yoke in loco e } \\
\text { observação de } \\
\text { processo. }\end{array}$ & Padronização \\
\hline
\end{tabular}

Nas colunas D e E é possível observar as fontes bibliográficas e fontes de evidência para avaliação de cada característica. As fontes de evidência correspondem às fontes de dados para verificar a existência da característica. Assim, uma fonte de evidências pode ser, por exemplo, um indicador, um formulário, uma norma, ou qualquer outro elemento que o avaliador possa auditar.

Por fim, na coluna $\mathrm{F}$ está colocado o princípio de PE associado a cada característica. Essa definição é importante porque mostra à organização quais os princípios da PE estão sendo comprometidos por deficiências no SGPK. 
Um aspecto importante da sistematização realizada é o fato de possibilitar a verificação das relações entre as categorias, conforme as características identificadas. A visualização de todas as características permite analisar, por exemplo, quais poderiam ser classificadas em outra categoria, evidenciando dessa forma as relações existentes entre as mesmas.

Resumidamente, pode-se afirmar que o método criado possibilita uma avaliação dos sistemas poka-yokes permitindo que cada organização realize melhorias focadas nas características daqueles que apresentam deficiências. Além disso, permite a organização projetar esses sistemas de acordo com categorias que conduzam a implementação de um SGPK.

\subsection{Recomendações para aplicar o método}

Um aspecto importante quando da utilização do método é a qualificação do avaliador. O avaliador precisa ter estar treinado no conceito de sistemas poka-yokes, não podendo estar influenciado por questões institucionais ou impregnado de um conhecimento prévio que não permita uma nova aprendizagem. Além disso, a pessoa responsável pela auditoria deve ter experiência nos conceitos de PE, dada a influência dos sistemas poka-yokes sobre esses conceitos. O avaliador precisa também estar treinado sobre a forma de fazer avaliação e as fontes de evidência associadas a cada característica. Por fim, o avaliador deve saber priorizar os critérios investigados. A metodologia sugere uma numeração para as características, entretanto no momento da avaliação deve haver sensibilidade para permitir a fluência no processo de avaliação.

Uma segunda questão que deve ser levada em consideração são as tarefas, o processo e as operações em que a avaliação está sendo realizada. Deve-se mensurar a importância de cada unidade da fábrica e ponderar a avaliação no contexto em que está sendo realizada. De fato, cabe a empresa identificar o nível de criticidade de cada processo e qual deve ser priorizado para melhoria ou implementação do sistema poka-yoke. Para definir quais os sistemas poka-yokes serão avaliados a organização deve realizar um mapa de fluxo de valor de seus processos. Através desse mapa, será possível verificar quais os processos e operações críticas, e consequentemente os sistemas pokayokes mais importantes. Além disso, o mapa de fluxo de valor possibilita a organização verificar onde novos poka-yokes poderiam ser implementados e também onde há categorias deficientes no SGPK. A empresa deve providenciar, anteriormente à realização da auditoria, um mapeamento dos sistemas poka-yokes. Esse mapeamento deve considerar as mesmas categorias que são usadas no sistema de avaliação. O mapeamento é importante, porque permite a empresa gerar fatos para análise dos sistemas poka-yokes, comparando-os com os resultados obtidos na avaliação.

\subsection{Tratamento das fontes de evidência}


As fontes de evidência elencadas no estudo foram classificadas conforme a proposta de Cambon et al. (2006) para sistemas de auditoria, e contemplam três tipos: estrutural, operacional e por desempenho. Por estrutural entendem-se todas as informações que estão associadas a documentos, como desenhos de projeto, normas, instruções de trabalho e planos de ação. Por operacional estão todas as informações coletadas com o depoimento dos operadores, encarregados, supervisores das operações e processos em que os poka-yokes estão implementados, além de observações in loco. Na categoria desempenho agrupam-se todos os indicadores provenientes de medições em relação às operações e processos que tenham poka-yokes implementados. Essa classificação está representada na Figura 2.

Figura 2 - Classificação das fontes de evidência

\begin{tabular}{|c|c|c|c|c|c|c|c|c|c|}
\hline \multirow{3}{*}{ 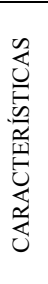 } & \multicolumn{4}{|c|}{ FONTES DE EVIDÊNCIA } & \multirow{3}{*}{ 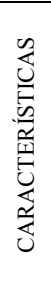 } & \multicolumn{4}{|c|}{ FONTES DE EVIDÊNCIA } \\
\hline & \multirow{2}{*}{ 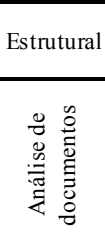 } & \multirow{2}{*}{ 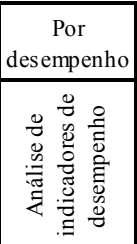 } & \multicolumn{2}{|c|}{ Operacional } & & \multirow{2}{*}{ 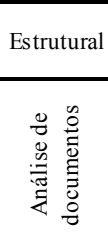 } & \multirow{2}{*}{ 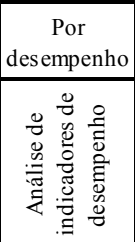 } & \multicolumn{2}{|c|}{ Operacional } \\
\hline & & & 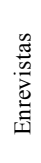 & 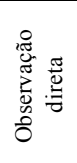 & & & & 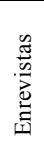 & 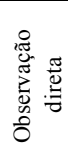 \\
\hline $\mathrm{C} 01$ & & & & & $\mathrm{C} 16$ & & & & \\
\hline $\mathrm{C} 02$ & & & & & $\mathrm{C} 17$ & & & & \\
\hline $\mathrm{C} 03$ & & & & & $\mathrm{C} 18$ & & & & \\
\hline $\mathrm{C} 04$ & & & & & $\mathrm{C} 19$ & & & & \\
\hline $\mathrm{C} 05$ & & & & & $\mathrm{C} 20$ & & & & \\
\hline $\mathrm{C} 06$ & & & & & $\mathrm{C} 21$ & & & & \\
\hline $\mathrm{C} 07$ & & & & & $\mathrm{C} 22$ & & & & \\
\hline $\mathrm{C} 08$ & & & & & $\mathrm{C} 23$ & & & & \\
\hline $\mathrm{C} 09$ & & & & & $\mathrm{C} 24$ & & & & \\
\hline $\mathrm{C} 10$ & & & & & $\mathrm{C} 25$ & & & & \\
\hline $\mathrm{C} 11$ & & & & & $\mathrm{C} 26$ & & & & \\
\hline $\mathrm{C} 12$ & & & & & $\mathrm{C} 27$ & & & & \\
\hline $\mathrm{C} 13$ & & & & & $\mathrm{C} 28$ & & & & \\
\hline $\mathrm{C} 14$ & & & & & $\mathrm{C} 29$ & & & & \\
\hline $\mathrm{C} 15$ & & & & & $\mathrm{C} 30$ & & & & \\
\hline
\end{tabular}

\section{Avaliação de sistemas poka-yokes}

As diretrizes para avaliação de poka-yokes foram aplicadas na planta de uma empresa multinacional de grande porte, que possui uma gama variada de produtos destinados às montadoras de automóveis, mercado de reposição automotiva e em menor escala para companhias petrolíferas, aeronáutica e aeroespacial. A empresa tem sistemas de gestão da qualidade e gestão ambiental que vem sendo desenvolvido faz 25 anos e é certificado com base nas normas NBR ISO 9001: 2007 e NBR ISO 14000: 2000, respectivamente. Além disso, a empresa vem implantando práticas de PE há cerca de 10 anos.

A empresa possui um sistema PE, baseado no Sistema Toyota de Produção. O sistema produtivo está organizado através de cinco circuitos (assim denominados pela empresa): qualidade, quantidade, lead time, flexibilidade e atendimento. O circuito da qualidade é composto por todas as políticas e ferramentas da qualidade utilizadas pela empresa, como por exemplo, auditoria, controle 
estatístico da qualidade, indicadores, sistemas poka-yokes, entre outros. O circuito quantidade é composto pelas políticas de produção adotadas, indicadores e metas de produção, controle de estoque e formas de programação da produção. O circuito lead time é responsável pelo controle dos tempos associados as operações e pela definição dos mapas de fluxo de valor da empresa. As informações obtidas através do circuito qualidade são importantes critérios para selecionar quais os poka-yokes devem ser submetidos ao método de avaliação. O circuito flexibilidade é responsável pelo combate a perdas na fábrica, associadas principalmente a redução dos tempos não produtivos como transporte e setup. As informações originadas nesse circuito são importantes para desenvolver sistemas poka-yokes, visto que em alguns casos são indicadores de problemas solucionáveis através destes sistemas. O circuito atendimento é responsável pela disponibilização do recurso produtivo. Nesse circuito há o acompanhamento do índice de rendimento operacional global (IROG) de cada estação de trabalho com acompanhamento de todas as interrupções de funcionamento e também os controles de padronização de desenvolvimento associados à gestão visual praticada pela empresa.

O fato da empresa apresentar esse envolvimento com a qualidade e com a produção enxuta fez com que se tornasse um estudo de caso adequado para o método de avaliação de poka-yoke proposto nessa pesquisa. A empresa tem uma estrutura de gestão de poka-yokes, com áreas dentro da fábrica chamadas de PRESET onde os sistemas poka-yokes são sistematicamente verificados anteriormente e posteriormente a sua utilização. Além disso, existe um setor que controla a validade de aferição dos poka-yokes, para tipo e especificidade de cada sistema poka-yoke. Essa estrutura é muito importante para o tipo de avaliação realizado, haja vista a facilidade para obtenção de informações.

Conceitualmente a empresa em estudo considera sistemas poka-yokes como todos os dispositivos capazes de realizar a inspeção 100\% automática e que detectam a ocorrência de erros. Erros, na concepção da empresa, é tudo aquilo que gera refugo ou retrabalho. Essa definição foi obtida junto ao coordenador do circuito qualidade, esse coordenador controla o conceito e o funcionamento de tudo que está associado ao seu circuito.

$\mathrm{Na}$ primeira etapa do estudo de caso, foi realizado um treinamento com as pessoas envolvidas na avaliação que seria realizada (analistas), explicando o objetivo da ferramenta, seu funcionamento e sua importância. Além disso, no treinamento foram identificados potenciais avaliadores de sistemas poka-yokes que poderiam replicar o método independente da colaboração do pesquisador.

$\mathrm{Na}$ segunda etapa, foi realizada a definição da unidade do sistema de manufatura que seria avaliada. A planta investigada é composta de sete unidades de manufatura, sendo que cada uma apresenta diferentes processos produtivos. A unidade escolhida foi determinada por representantes da empresa, visto que eles consideravam prioritária a avaliação do SGPK dessa unidade, que 
trabalhava exclusivamente com o fornecimento para montadoras e fabrica produtos de alto valor agregado. A partir dessa definição, foi realizado um encontro com encarregados pelo setor e operadores do setor, além do analista anteriormente treinado. O encontro tinha por objetivo mostrar a sistemática do trabalho, esclarecer dúvidas e obter informações iniciais com relação aos sistemas poka-yokes.

$\mathrm{Na}$ terceira etapa, foi realizada a avaliação dos sistemas poka-yokes. A avaliação foi realizada pelo método anteriormente apresentado. A avaliação ocorreu ao longo de três visitas: (a) na primeira, foi realizado a apresentação do método para o coordenador da área e explicado o objetivo do trabalho, totalizando uma hora; (b) na segunda visita, foi realizada a definição de quais poka-yokes seriam avaliados e realizada a avaliação desses, totalizando cinco horas; (c) os dados foram compilados e apresentados a representantes da empresa em uma terceira visita. As informações obtidas permitiram que fossem projetadas ações de melhoria dos sistemas poka-yokes com a definição de responsáveis, prazos, indicadores de acompanhamento e exequibilidade econômica de realização, totalizando uma hora de visita. Por razões de sigilo exigidas pela empresa, este trabalho não apresenta registros fotográficos dos poka-yokes avaliados e o plano de ação de melhorias dos sistemas poka-yokes.

Os poka-yokes foram selecionados de acordo com os pontos críticos identificados no mapa de fluxo de valor do processo em que o sistema poka-yoke está implementado. Os pontos críticos são todos os Capacity Constraint Resource (CCR).

Dessa forma, dentro do universo de 43 poka-yokes disponíveis na unidade analisada e assim considerados pela empresa, determinou-se o número de sete avaliações necessárias. Para finalizar foi realizada uma análise dos dados coletados, com a participação dos envolvidos na coleta e decidido quais seriam as ações de melhoria.

O tratamento dos dados para totalização das categorias pelo número de características foi realizado da seguinte forma. Para cada característica foi atribuído o valor de quanto ela compunha no total da categoria. Por exemplo, a categoria manutenção é composta por quatro características, para cada uma foi atribuído o valor de 0,25 , que foi totalizado para categoria manutenção quando constatado que existia a característica no sistema poka-yoke. Essa sistemática foi realizada para todas as categorias, sendo que o máximo que cada uma poderia atingir é um (sem realização de uma ponderação), visto que este é o valor de cada categoria quando analisados como atributos.

Posteriormente foram atribuídos pesos para cada uma das categorias, conforme o grau de importância de cada uma das categorias em relação ao grau de importância para o sistema de manufatura analisado. No estudo as categorias de controle de qualidade e gestão visual foram as que receberam os maiores pesos, correspondendo respectivamente a $22 \%$ e $20 \%$. A categoria estabilidade da produção foi atribuída $18 \%$ do peso total e a categoria projeto e operação $17 \%$. 
Finalmente as categorias manutenção e viabilidade econômica receberam, respectivamente, os pesos $13 \%$ e $10 \%$.

A organização dessa forma permitiu verificar quais categorias estavam atendendo plenamente o sistema poka-yoke, quais estavam atendendo parcialmente, e quais estavam totalmente defasadas. Isto é importante, porque permite que a empresa focalize as ações de melhoria para cada poka-yoke ou, quando se verifica que a mesma categoria está defasada para todos os sistemas poka-yokes avaliados, desenvolva um trabalho único para uma determinada categoria do SGPK.

A avaliação de cada característica foi realizada por meio das fontes de evidência descritas na Quadro 2 e sinalizadas na forma de auditoria na Figura 5. Para a avaliação através das fontes de evidência, foi necessário criar uma planilha de avaliação, apresentada na Figura 3. Durante a avaliação deve-se usar a planilha proposta para marcar quais características fazem parte do sistema poka-yoke que está sendo avaliado. Posteriormente, essa planilha é utilizada para a elaboração dos resultados.

Figura 3 - Planilha de avaliação do SGPK

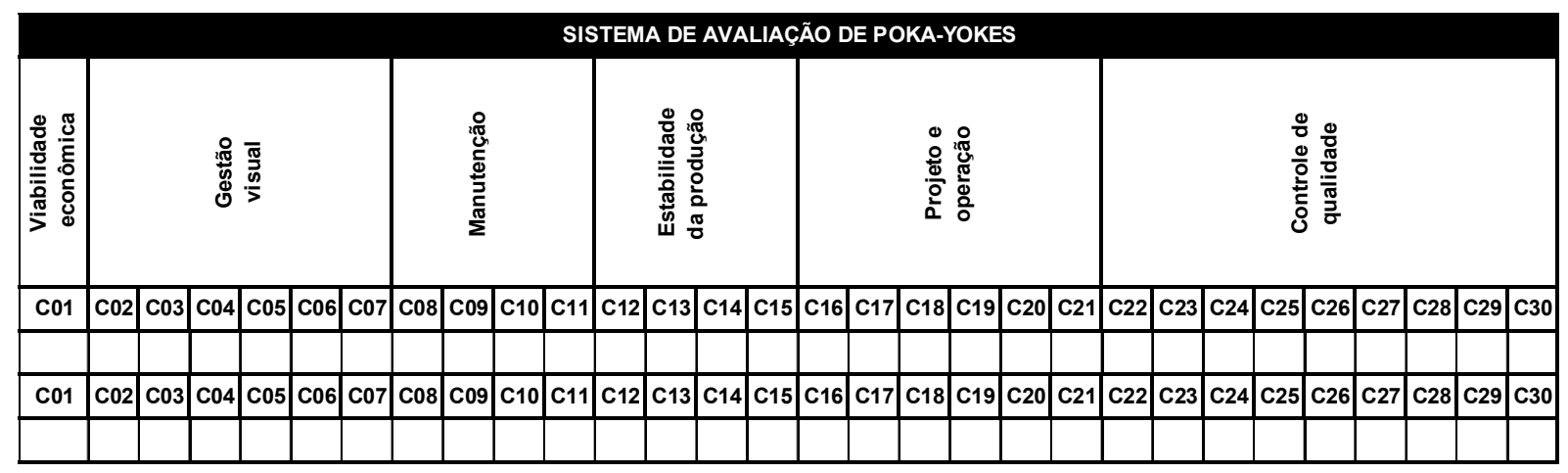

Salienta-se que os poka-yokes foram selecionados para análise, conforme o conceito da empresa para esses sistemas. Isto é importante porque tem um impacto direto sobre os resultados obtidos, visto que o conceito adotado pela empresa para definir os seus sistemas poka-yokes é impreciso conceitualmente, quando comparado ao conceito definido neste trabalho para esses sistemas.

\section{Resultados}

A Figura 4 apresenta os resultados da avaliação dos sete sistemas poka-yokes investigados. As categorias foram ponderadas conforme a sua importância para o sistema de manufatura auditado. Contudo, as características são tratadas como atributos, conforme justificado anteriormente. Dessa forma, na análise dos dados é realizada uma totalização das categorias pelo número de características distribuídas em cada uma e esse valor é multiplicado pelo peso de cada categoria. A 
análise dessa maneira permitiu que fossem verificados graficamente os pontos fortes e pontos fracos de cada categoria, além de proporcionar um indicador numérico para o sistema poka-yoke, indicando o seu respectivo potencial de melhoria.

Figura 4 - Avaliação dos sistemas poka-yokes

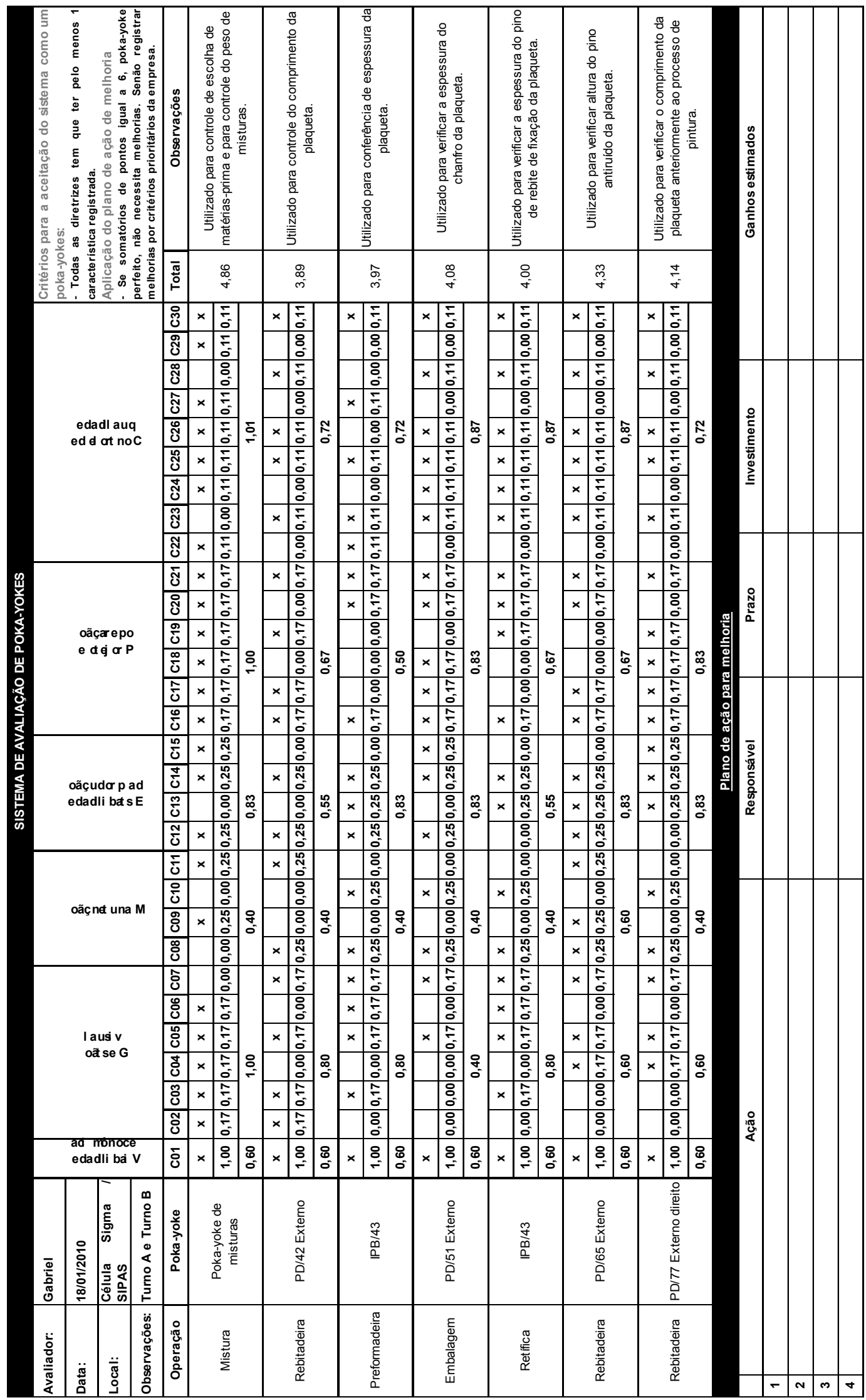


A sistematização proposta deu origem a Figura 5, que apresenta o desempenho de cada sistema poka-yoke em relação à avaliação realizada. Na coluna $\mathrm{A}$, está descrita a operação e o nome do sistema poka-yoke, enquanto na coluna B, o resultado da avaliação do sistema poka-yoke em forma de gráfico. É possível observar que apenas a categoria viabilidade econômica apresenta um comportamento similar para todos os sistemas avaliados, isto porque reflete a análise de uma única característica e no caso todos os sistemas avaliados apresentam essa característica.

Embora o sistema poka-yoke de misturas seja o que apresenta o melhor resultado (pontuação de 4,86 observada na Figura 4), é possível perceber necessidade de melhorias principalmente na categoria manutenção, visto que não existe manutenção preventiva e não há histórico de manutenções corretivas realizadas. Ações pontuais, como a realização da gestão visual padronizada e aferição periódica do sistema poka-yoke, em relação às categorias estabilidade da produção e controle de qualidade, também poderiam ser focalizadas para garantir a melhoria do sistema pokayoke.

O sistema poka-yoke IPB/43 da operação de preforma apresentou resultados bons para a categoria estabilidade da produção. Todavia, as demais categorias necessitam melhorias. A questão de projeto e operação está especialmente deficiente. Não foram consideradas as questões de flexibilidade do operador, bem como segurança. Além disso, o sistema poka-yoke não combate outras causas de problemas, além da causa raiz identificada, conforme recomenda o método. A sua função no controle de qualidade também está carente de complementação, pois, observa-se que não há verificação de funcionalidades no início da jornada de trabalho e a inspeção não se realiza de forma totalmente automatizada. A manutenção carece de um histórico de controle, apesar da existência de um plano preventivo específico para o sistema poka-yoke não há um detalhamento da forma como o procedimento de manutenção preventiva foi realizado.

$\mathrm{O}$ sistema poka-yoke $\mathrm{PD} / 51$ Externo tem bons resultados para a categoria projeto e operação, estabilidade da produção e controle de qualidade. A principal deficiência verificada nesse sistema poka-yoke é em relação à gestão visual. O sistema não apresenta elementos de gestão visual, além daqueles que foram verificados para todos os outros poka-yokes. As ações de melhoria deveriam estar centradas nessa categoria. Além disso, a categoria manutenção poderia ser melhorada na questão do controle de histórico de manutenção.

O sistema poka-yoke IPB/43 da operação de retífica apresentou bons resultados para a categoria controle de qualidade. As categorias que apresentaram maior deficiência foram manutenção e estabilidade de produção. A melhoria associada à manutenção é principalmente pela necessidade de controle de um histórico de manutenção. Para a categoria estabilidade da produção 
as melhorias devem estar direcionadas para autonomia do operador sobre o processo, passando este a controlar o reinicio do processo a partir do tratamento da causa raiz.

O sistema poka-yoke IPB/65 Externo apresentou bons resultados em todas nas categorias, exceto a categoria de gestão visual, que necessita de melhorias. O sistema poka-yoke carece de uma documentação detalhada sobre o seu funcionamento, e também da forma de verificar a sua funcionalidade. Nem mesmo a instrução de trabalho associada a estação de trabalho detalha como é o funcionamento do sistema poka-yoke. Além disso, não há um indicador em relação a esse sistema poka-yoke para verificar os resultados obtidos com a sua implementação.

Figura 5 - Resultado da avaliação dos sistemas poka-yokes

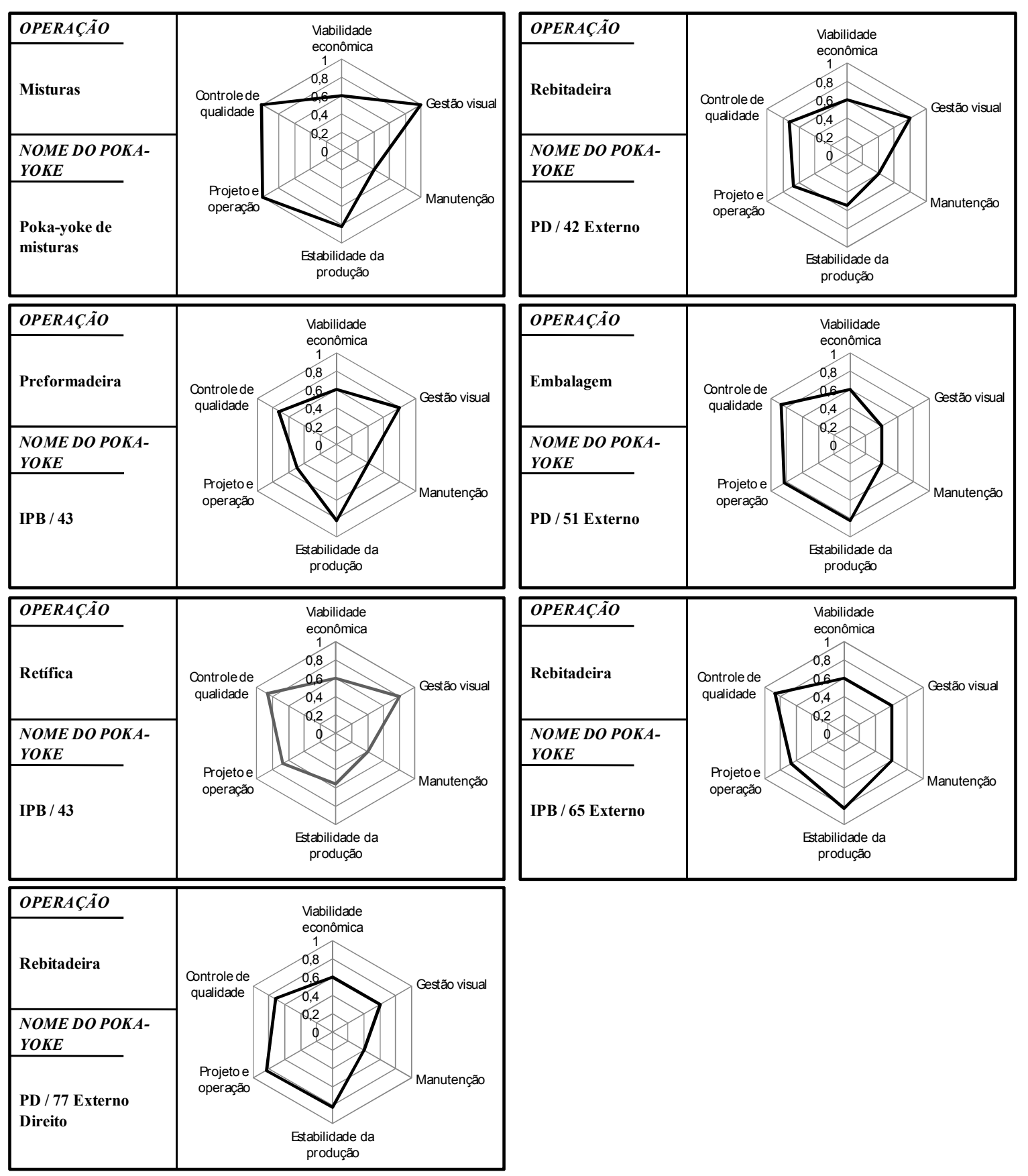


Por fim, o último sistema poka-yoke avaliado foi o PD/77 Externo Direito. Esse sistema poka-yoke apresentou bons resultados para as categorias estabilidade da produção e projeto e operação. Esse sistema poka-yoke necessita de melhorias especialmente na categoria controle de qualidade. Uma melhoria seria em relação a função do poka-yoke, deixando de ser reativa para ser pró-ativa. Além disso, outra melhoria deveria ser a instauração de um procedimento para verificação funcional, que atestaria a regularidade do poka-yoke a cada início de jornada de trabalho.

De posse dessas informações, ao final do estudo foi realizado um plano de ação para implementar as melhorias constatadas. Esse plano de ação foi realizado de acordo com o modelo utilizado pela empresa em estudo. Por questões de sigilo, o plano de ação não pode ser apresentado nesse trabalho. As ações estavam concentradas nas sugestões de melhorias verificadas nesse estudo, com definição de responsáveis e indicadores de acompanhamento para posterior análise do que seria implementado.

\section{Conclusões}

Tendo em vista atingir o objetivo deste artigo foram propostas diretrizes para a avaliação de sistemas poka-yokes. Essas diretrizes foram desdobradas em categorias, com respectivas características. O desenvolvimento das diretrizes foi baseado na revisão da literatura e na análise de melhores práticas desenvolvidas em quatro organizações. O escopo do método de avaliação constituído este baseado em seis categorias em que se distribuem 30 características para avaliação. O estudo de caso realizado ocorreu em uma organização do ramo metal-mecânico, sendo que o motivo para a seleção foi o fato da empresa utilizar práticas de PE, e por consequência o desenvolvimento de sistemas poka-yokes em seu cotidiano. A empresa é composta de seis sistemas de manufatura diferentes. O critério utilizado para a definição de qual sistema produtivo seria utilizado foi determinado pela análise do mapa de fluxo de valor, conforme recomenda o método, possibilitando a identificação do ambiente onde maior valor é agregado ao produto final.

Os estudos realizados demonstraram que a ausência de um conceito padronizado para sistemas poka-yokes tem um impacto sobre a avaliação realizada. O conceito em relação ao pokayoke é importante porque unifica a comunicação entre aqueles que são avaliados e os que estão avaliando. Normalmente a empresa avaliada apresenta uma conceituação em relação ao sistema poka-yoke utilizado, todavia, o avaliador está treinado para avaliar o sistema poka-yoke de acordo com um conceito próprio, alinhado as categorias de avaliação e que pode ser diferente do utilizado pela empresa. Dessa forma, existem expectativas diferentes em relação à avaliação que será realizada. Essas expectativas acabam por impactar o resultado final, visto que ocorrem 
questionamentos sobre a validade do método de avaliação por parte do avaliado e sobre os tipos de melhoria que serão implementadas por parte do avaliador.

Podem existir características não contempladas no total de categorias definidas e que podem exercer importância em relação ao sistema de avaliação elaborado. Quanto ao método pode-se afirmar que a utilização das categorias de avaliação para o desenvolvimento de sistemas poka-yokes que serão implementados é uma alternativa robusta, visto que garante a observação de aspectos associados ao combate das perdas.

Utilizando o conceito que um sistema poka-yoke é um mecanismo de prevenção e detecção de perdas, observa-se que o sistema de avaliação elaborado pode ser uma alternativa para o desenvolvimento de novos sistemas poka-yokes. De fato, o sistema de avaliação verifica a eficácia e a eficiência do SGPK em relação ao combate de perdas, proporcionando o panorama para o desenvolvimento de novos sistemas a partir de categorias e características estruturadas.

A caracterização de um sistema poka-yoke também passa pelo avaliador. O conhecimento associado e o perfil do avaliador são importantes para respaldar a implementação de posteriores melhorias. O avaliador deve conhecer a dinâmica do processo que está sendo avaliado. Esse conhecimento permite que o avaliador possa verificar com segurança as fontes de evidência analisadas, o que é importante para validar a avaliação. Além disso, o conhecimento do processo é importante, pois auxilia na definição de poka-yokes e como eles devem ser avaliados, visto que há um domínio sobre o fluxo de valor do processo, e consequentemente sobre os gargalos.

No estudo de caso foram coletadas as informações referentes a comportamento dos sistemas poka-yokes em relação às diretrizes propostas, elucidando os principais aspectos de melhoria. As melhorias determinadas com a avaliação são apenas sugeridas para implementação. Não existe um controle para avaliar a efetividade de cada melhoria ou mesmo se as melhorias foram implementadas. Nesse sentido a avaliação deveria ser realizada periodicamente, e cada melhoria proposta nas avaliações anteriores e que não foi realizada, deve ter um registro associado. Além disso, a utilização de uma periodicidade de avaliação deveria ser adotada, para que fosse controlada a evolução do sistema poka-yoke, ou mesmo a sua descontinuidade de uso.

O fato de vincular a característica do sistema poka-yoke avaliado a um princípio de PE é importante para mostrar o impacto desses sistemas sobre o sistema de manufatura. No estudo, os princípios afetados foram: (i) controle de perdas; (ii) padronização; (iii) melhoria contínua; (iv) autonomação. Através do princípio de PE associado a cada característica é possível que a organização avaliada possa mensurar qual tipo de princípio de produção está defasado em relação ao seu sistema de manufatura. Evidentemente que a avaliação de um número pequeno de sistemas poka-yokes não vai subsidiar informações para análise real das deficiências da organização. Contudo, quando são analisados os sistemas poka-yokes dos processos críticos do fluxo de valor, 
conforme recomenda o método, a amostra é suficiente para indicar a(s) deficiência(s). De fato, é gerado para a empresa um grupo de informações que permite uma análise gerencial em relação o que deve ser mudado no sistema de manufatura para garantir o combate efetivo de perdas.

Outro aspecto associado a PE é a importância dos mapas de fluxo de valor. Notadamente quando a empresa identifica onde estão os pontos críticos do fluxo de valor é fácil identificar os sistemas poka-yokes que serão avaliados. Portanto, pode-se afirmar que empresas que apresentam práticas de PE, podem visualizar o impacto sistêmico de melhorias ou deficiências de seus sistemas poka-yokes, enquanto que as demais organizações enfrentam dificuldades para a realização da avaliação de seus sistemas poka-yokes.

\begin{abstract}
This study presents guidelines to evaluate a management poka-yoke system. A literature review and the best practices review in organizations of branch metallurgy, metalworking and automotive preceded the development of the guidelines. Also, a case study was carried out with seven poka-yoke systems to validate the guidelines development in a company that uses lean production practices. The guidelines propose that poka-yoke systems be evaluated on a set of categories, that are unfolded in 30 features capable of evaluation. The application of guidelines in the case study allowed to conclude that: (a) some devices understood by companies as poka-yoke may be far from the attributes necessary to feature then as poka-yoke systems; (b) the evaluator needs to have technical knowledge about the process where the poka-yoke is installed; (c) the guidelines proposed can be used as allowance for the development of new poka-yoke systems; (d) the application of the guidelines tends to be more useful for companies that have lean production initiatives, because they can see the systemic impact by poka-yoke systems.
\end{abstract}

Key-words: poka-yoke, performance measurement, evaluation..

\title{
Referências
}

BENDELL, T., PENSON, R., CARR, S. The quality gurus - their approaches described and considered. Managing Service Quality, v.5, n.6, p.44-48, 1995.

cross ${ }^{\text {ref }}$

BLACK, J. T. O projeto da fábrica com futuro. Tradução: Gustavo Kannenberg e Flávio Pizzato. Porto Alegre: Editora Artes Médicas Sul Ltda, 1998. Título original: The design of the factory with a future.

CONNOR, G. Poka-yoke: Human-Proof your Process. Journal of Industrial Maintenance e Plant Operations, p.12-14, jun. 2006.

CONTI, R., ANGELIS, J., COOPER, C., FARAGHER, B., GILL, C. The effects of lean production on worker job stress. International Journal of Operations and Production Management, v.26, n.9, p.1013-1038, 2006.

cross ${ }^{\text {ref }}$

CROSBY, P. B. Qualidade é investimento: a arte de garantir a qualidade. Tradução: Áurea Weissenberg. Rio de Janeiro: Livraria José Olímpio S.A., 1999. Título Original: Quality is free.

DEMING, W. E. Qualidade: a revolução da administração. Tradução: Clave Comunicações e Recursos Humanos SC Ltda. Rio de Janeiro: Editora Marques Saraiva S.A., 1990.

DIAS, J. R., INFANTE, P. Controls Charts with predetermined sampling intervals. International Journal of Quality and Reliability Management, v.25, n.4, p.423-435, 2008.

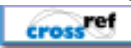


FEIGENBAUM, A. V. Controle de Qualidade Total Gestão e Sistemas. Tradução: Regina Cláudia Loverri. São Paulo: Editora McGraw-Hill Ltda, 1994.

FISHER, M. Process improvement by poka-yoke. Work Study MCB University Press v.48, n.7, p.264-266, 1999.

FORMOSO, C. T., SANTOS, A., POWELL, J. A. An exploratory study on the applicability of process transparency in construction sites. Journal of Construction Research, v.3, n.1, p.35-54, 2002

crossef

GHINATO, P. O Sistema Toyota de Produção: mais do que simplesmente o just-in-time. Caxias do Sul, Editora da UCS, 1996.

GHINATO, P. Quality control methods: toward modern approaches through well estabilished principles. Total Quality Management Journal, v.9, n.6, dez. 1998.

GROUT, J. Mistake-proofing the Design of the Health Care Processes. Rockville, AHRQ, 2007.

HINCKLEY, C. M. Combining mistake-proofing and Jidoka to achieve world class quality in clinical chemistry. General Paper, Springer-Verlag, v.12 p.223-230, mar. 2007.

HIRATA, H. S. Sobre o "Modelo" Japonês: automatização, novas formas de organização e de relações de trabalho. São Paulo, Editora da USP, 1993.

HOLLNAGEL, E. Barrier analysis and accident prevention: how to improve safety by understanding the nature of accidents rather than finding their causes, 2004. 37p.

INSTITUTO LEAN. Glossário para Praticante do Pensamento Lean. Lean Institute Brasil, São Paulo, 2003. Apostila.

ISHIKAWA, K. Controle de qualidade total: à maneira japonesa. Tradução: Iliana Torres. Rio de Janeiro: Editora Campus Ltda, 1993. Título orginal: What is Total Quality Control?

JURAN, J. M., GRYNA, F.M. Controle da qualidade: Conceitos, políticas e filosofia da qualidade. Tradução: Maria Cláudia de Oliveira dos Santos. São Paulo: Editora McGraw-Hill Ltda, 1991. Título original: Juran’s Quality Control Handbook - 4th edition.

LIKER, K. J., MEIER, D. O Modelo Toyota de Produção: Manual de aplicação. Tradução: Lene Belon Ribeiro. Porto Alegre: Bookman, 2007. 432p. Título original: The Toyota Way Fieldbook.

KAMADA, S. Estabilidade de Produção da Toyota do Brasil. Lean Institute Brasil, 2007. Disponível em http://www.lean.org.br/bases.php?\&interno=artigo_44.

MCGEE, D. Lean and Six Sigma: A Holistic Approach to Process Improvement. In.: ASQ- American Society for Quality Congress, Proceedings... Denver, USA, nov. 2005.

MIDDLETON, P. Lean Software Development: two case studies. Software Quality Journal, v.9, p.241-252, 2001. cross ${ }^{\text {ref }}$

MONTGOMERY, D. C. Introdução ao controle estatístico da qualidade. 4.ed. Rio e Janeiro: LTC, 2004.

MOORES, B. A glossary of terms encountered in quality and customer service. International Journal of Health Quality Assurance, v.9, n.5, p.24-36, 1996.

cross'

NIKKAN. K. S. Poka-yoke: Improving product quality by preventing defects. Portland: Productivity Press, 1988.

PATEL, S., DALE, B. G., SHAW, P. Set-up time reduction and mistake proofing methods: an examination in precision component manufacturing. The TQM Magazine, v.13, n.3, p.175-179, 2001. 
. Set-up time reduction and mistake proofing methods: a study of application in small company. Journal of Business Process Management, v.7, n.1, p.65-75, 2001.

cross ${ }^{\text {ref }}$

PLONKA, F. E. Developing a Lean and Agile Work Force. Journal of Human Factors and Ergonomics in Manufacturing, v.7, n.1, p.11-27, 1997.

cross ${ }^{\text {ref }}$

PRAJAPATI, D. R., MAHAPATRA, P. B. A simple and effective X chart for process monitoring. International Journal of Quality and Reliability Management, v.25, n.5, p.508-531, 2008.

cross ${ }^{\text {ref }}$

REASON, J. Managing the risks of organizational accidents. England, Ashgate Publishing Limited, 1997. p.61-83.

SANTOS, A., POWELL, J. Potencial of poka-yoke devices to reduce variability in construction. Berkeley, University of California, p.51-62, 1999.

SAURIN, T. A., JACQUES, J., HENRIQSON, E., JÚNIOR, G. C. Análise de uma barreira de classificação contra acidentes em produtos e processos. XXVII Encontro Nacional de Engenharia de produção. Anais... Foz do Iguaçu: ENEGEP, 2007.

SHEWHART, W. A. Economic Control of Quality of Manufactured Product. New York: Van Nostrand, 1931.

SHIMBUN, N. K. Poka-yoke: Improving Product Quality by Preventing Defects. Portland, MA: Productivity Press, 1988. Título Original: Pokayoke dai zukan.

SHINGO, S. Zero Quality Control: Source Inspection and the Poka-yoke System. Cambridge, MA: Productivity Press, 1988 .

. O Sistema Toyota de Produção: do ponto de vista da engenharia de produção. Tradução de Eduardo Schaan. Porto Alegre: Artemed ${ }^{\circledR}$ Editora S.A., 1996. 291p. Título original: A study of the Toyota Production System from an Industrial Engineering Viewpoint.

Sistema de troca rápida de ferramenta: uma revolução nos sistemas produtivos. Tradução de Eduardo Schaan e Cristina Schumacher. Porto Alegre: Artemed® Editora S.A., 2000, 327p. Título original: A revolution in manufacturing: the SMED system.

STEWART, D. M., GROUT, J. R. The Human Side of mistake-proofing. Journal of Production and Operations Management, v.10, n.4, p.440-459, 2001.

TAKASAN, K. TPM: confiabilidade e otimização de equipamentos industriais. In: Seminário Internacional de TPM, 1992, Tokyo. Anais... Tokyo: JIPM, 1992.

WANG, W., ZHANG, W. Early defect identification: application of statistical process control methods. Journal of Quality in Maintenance Engineering, v.14, n.3, p.225-236, 2008.

\section{Dados dos autores:}

\section{Nome completo: Gabriel Vidor}

Filiação institucional: Universidade Federal do Rio Grande do Sul

Departamento: DEPROT - Departamento de Engenharia de Produção e Transportes

Função ou cargo ocupado: bolsista de doutorado

Endereço completo para correspondência (bairro, cidade, estado, país e CEP): Rua Nereu Pinto

Presntes, 186. Bairro Cristo Redentor. Caxias do Sul. RS. Brasil. CEP: 95086-240. 
Telefones para contato: (54) 99826557

e-mail:gvidor@producao.ufrgs.br

Nome completo: Tarcísio Abreu Saurin

Filiação institucional: Universidade Federal do Rio Grande do Sul

Departamento: DEPROT - Departamento de Engenharia de Produção e Transportes

Função ou cargo ocupado: Professor

Endereço completo para correspondência (bairro, cidade, estado, país e CEP): Av. Osvaldo Aranha, $99-5^{\circ}$ andar. Bairro Centro. Porto Alegre. RS. CEP 90.035-190

Telefones para contato: (51) 96282554

e-mail:saurin@ufrgs.br 